Po ne ha identificati 16 . La nested-PCR di riferimento ha inoltre identificato $8 \mathrm{Pm}$, mentre la nuova real-time-PCR per $P m$ ne ha identificati 6. La nuova real-time-PCR per $P m / P o$ non ha mostrato cross-reattività con il DNA delle altre specie di plasmodi e con quello umano.

Conclusioni. I nostri dati suggeriscono che alcune infezioni da $P o$ e $P m$ possono essere non diagnosticate mediante esame microscopico e 18S-rDNA-PCRs. La nuova real-timePCR per $\mathrm{Po} / \mathrm{Pm}$ si è rivelata complessivamente specifica e sensibile ma, nel nostro studio, non in grado di rivelare $\mathrm{Po} / \mathrm{Pm}$ in $4 / 2$ casi, rispettivamente, rispetto alla nested-PCR di riferimento. Non disponiamo quindi al momento, di un saggio di real-time-PCR che possa sostituire la nested-PCR di riferimento, più lunga e indaginosa, per la diagnosi di laboratorio di malaria.

\title{
177
}

\section{RIVELAZIONE DI P. OVALE E P. MALARIAE MEDIANTE UN NUOVO SAGGIO DI REAL-TIME PCR.}

\author{
Calderaro A., Piccolo G., Perandin F.', Ricci L.', Manca N.', \\ Dettori G., Chezzi C.
}

Dipartimento di Patologia e Medicina di Laboratorio, Sezione di Microbiologia, Università degli Studi di Parma; 'Dipartimento di Medicina Sperimentale ed Applicata, Cattedra di Microbiologia, Università degli Studi di Brescia; ${ }^{2}$ Arcispedale di Reggio Emilia.

Introduzione. Negli ultimi anni l'utilizzo dei saggi di PCR per la diagnosi di malaria ha evidenziato un aumento della prevalenza in Italia dei casi d'infezione da P.ovale $\left(P_{0}\right)$ e P.malariae $(P m)$, sottostimata nel passato mediante esame microscopico. D'altra parte è stata dimostrata la presenza di ceppi di $\mathrm{Po}$ e $\mathrm{Pm}$ mutati nel gene 18S-rDNA che potrebbero non essere rivelati dai saggi di PCR basati su questo bersaglio. Qui riportiamo la valutazione di un nuovo saggio di real-time-PCR, descritto in letteratura, per l'identificazione di $P o$ e $P m$, rispettivamente.

Metodi. Centosette campioni di sangue di altrettanti pazienti con sospetta malaria sono stati sottoposti ad osservazione microscopica, a real-time-PCR per $\mathrm{Po} / \mathrm{Pm}$ e ai sistemi di riferimento da noi utilizzati per la diagnosi molecolare di malaria: una nested-PCR per $P$.falciparum $(P f) / P$.vivax $(P v) / P o / P m$ e una real-time-PCR per $P f / P v / P o$.

Risultati. Mediante esame microscopico i campioni erano: 9 positivi per $P f, 12$ per $P v, 7$ per $P o, 3$ per $P m, 1$ per $P v / P o, 2$ per Plasmodium spp. e 73 erano negativi. La nested-PCR e la real-time-PCR di riferimento hanno identificato 20 e 10 $P$.ovale, rispettivamente, mentre la nuova real-time-PCR per 